\title{
Aerosol variability and atmospheric transport in the Himalayan region from CALIOP 2007-2010 observations
}

\author{
S. Bucci ${ }^{1,2}$, C. Cagnazzo ${ }^{1}$, F. Cairo ${ }^{1}$, L. Di Liberto ${ }^{1}$, and F. Fierli ${ }^{1}$ \\ ${ }^{1}$ Institute for Atmospheric Sciences and Climate, ISAC-CNR, Rome, Italy \\ ${ }^{2}$ Department of Physics, Ferrara University, Ferrara, Italy \\ Correspondence to: F. Fierli (f.fierli@isac.cnr.it)
}

Received: 18 April 2013 - Published in Atmos. Chem. Phys. Discuss.: 11 June 2013

Revised: 16 November 2013 - Accepted: 15 February 2014 - Published: 5 May 2014

\begin{abstract}
This work quantifies the spatial distribution of different aerosol types, their seasonal variability and sources.The analysis of four years of CALIOP (CloudAerosol LIdar with Orthogonal Polarization) vertically resolved aerosol data allows the identification of spatial patterns of desert dust and carbonaceous particles in different atmospheric layers. Clusters of Lagrangian back trajectories highlight the transport pathways from source regions during the dusty spring season. The analysis shows a prevalence of dust; at low heights it occurs frequently (up to $70 \%$ of available observations) and is distributed north of the Tibetan Plateau with a main contribution from the Gobi and Taklamakan deserts, and west of the Tibetan Plateau, originating from the deserts of southwest Asia and advected by the Westerlies. Above the Himalayas the dust amount is minor but still not negligible (occurrence around 20\%) and mainly affected by the transport from more distant deserts sources (Sahara and Arabian Peninsula). Carbonaceous aerosol, produced mainly in northern India and eastern China, is subject to shorter-range transport and is indeed observed closer to the sources, while there is a limited amount reaching the top of the plateau. Data analysis reveals a clear seasonal variability in the frequencies of occurrence for the main aerosol types; dust is regulated principally by the monsoon dynamics, with maximal occurrence in spring. We also highlight relevant interannual differences, showing a larger presence of aerosol in the region during 2007 and 2008. The characterization of the aerosol spatial and temporal distribution in terms of observational frequency is a key piece of information that can be directly used for the evaluation of global aerosol models.
\end{abstract}

\section{Introduction}

Aerosol alters the radiative balance through absorption and scattering of the solar radiation (Lau et al., 2006) and influences cloud formation, greatly impacting the hydrological cycle (Kaufman et al., 2005). More recently, special focus has been given to the aerosol-related climatic processes in the south Asian region where the largest anthropogenic sources are located and where the presence of desert dust is relevant (Ramanathan et al., 2005; Lau et al., 2008; Bollasina et al., 2008). The increased presence of aerosol, especially in late spring, can lead to significant variations on the monsoon evolution and on the hydroclimate of the area: large aerosol load can lead to surface cooling caused by the reduction of incident solar radiation at the surface and increased heating of the troposphere caused by absorption (direct effect). On the other hand, aerosol can modify the upwelling above the Himalaya with an intensification of the Indian monsoon (the so-called elevated heat pump, or EHP) that is strongly linked to the dust concentration around the plateau during the spring season (Lau et al., 2006). In addition, aerosol can induce a change in cloud amount and precipitation through microphysics (indirect effect) (Menon et al., 2002; Ramanathan et al., 2005; Lau et al., 2006), acting as condensation nuclei or influencing the process of water evaporation through their impact on the radiative budget (Ramanathan et al., 2007). Moreover, the deposition of particulate on ice and snow affects their surface albedo and ice microphysics (Xu et al., 2009; Krinner et al., 2006), modifying the melting processes. Such variations can be spatially highly inhomogeneous (Naz et al., 2011; Raina, 2010), suggesting that those changes may be caused by local forcings and, among 
them, by the variable spatial distribution of particulate. In addiction Bonasoni et al. (2010) show that a strong level of pollutants can affect the southern Himalayas especially during the pre-monsoon period and that valley circulation may bring also chemicals emitted by local sources up to the plateau. A characterization of the aerosol spatial distribution, its variability at different timescales and the identification of its sources are therefore required to understand the role of both anthropogenic and natural aerosol in long-term climate change. Several studies have attempted to assess the aerosol amount and the processes that regulate its presence over the region by means of satellite observations: Menglin (2006) analyzed five years (2000-2005) of aerosols, clouds, water vapor and cirrus observations measured by the NASA Terra Moderate-Resolution Imaging Spectroradiometer (MODIS) to reveal seasonality and interannual variations of the atmospheric condition on the Tibetan Plateau (TP) and its link to the hydrological cycle; Xia et al. (2008) present seasonal and interannual variations of aerosol optical depth (AOD) using the Multiangle Imaging SpectroRadiometer (MISR) aerosol retrievals from May 2000 to May 2007 jointly with a study of the spatiotemporal characteristics of aerosol over the TP, derived from Stratospheric Aerosol and Gas Experiment II (SAGE II) data. The work adds the use of ground-based data to study the potential influence of dust storms originated in the Taklimakan Desert on AOD over the TP; Dey and Di Girolamo (2010) analyzed the spatial and temporal characteristics of aerosol properties, segregated by particle size and shape, over the Indian subcontinent over nine years (20002008) by means of AOD and Angström Exponent measured by MISR.

The introduction of the CALIPSO (Cloud-Aerosol Lidar and Infrared Pathfinder Satellite Observations) instruments offered new observational capabilities as the lidar CALIOP (Cloud-Aerosol LIdar with Orthogonal Polarization) gives fundamental information on the vertical distribution of airborne particulate. Some recent studies have already exploited CALIPSO data for aerosol studies over the Himalayan region; Mishra and Shibata (2012) produced, using aerosol profile data, vertical profiles of aerosol optical properties over the Indo-Gangetic belt, for a time period between June 2006 and December 2009. Kuhlmann and Quaas (2010) estimated the radiative forcing from different types of aerosol above the plateau to discuss the EHP hypothesis, while Gautam et al. (2009) characterized the dust burden in the 2007 and 2008 pre-monsoon seasons. Liu et al. (2008) estimated the spatial patterns of desert aerosol in 2007 and highlighted the possible dust transport pathways, identifying the plateau as a dynamical obstacle for the westerly jet flow.

The first objective of this work is to provide a characterization of the spatial distribution of different aerosol type over the region of the Himalayan Plateau based on CALIPSO observations and individuate the seasonal variability over four years (2007-2010). This work follows an approach similar to Liu et al. (2008) but extends the observations over a longer period and to different kinds of particulate. The second objective is to present an assessment of the boundary layer sources for the 2007-2010 pre-monsoon seasons based on Lagrangian numerical simulations. It is in fact necessary to investigate the role of distant desert areas since some studies evidenced the role of westerly winds during the pre-monsoon season (Bonasoni et al., 2010; Kayetha et al., 2007; Prasad et al., 2006). Also Liu et al. (2008), using Hysplit (Hybrid Single Particle Lagrangian Integrated Trajectory Model) back trajectories, showed that dust can be advected to the region from the Tarim Basin and the major deserts of northeastern India, Pakistan and Afghanistan.

\section{Data and methodology}

The CALIPSO satellite (Winker et al., 2007) was developed by NASA (National Aeronautics and Space Administration) and CNES (Centre National d'Etudes Spatiales) and measures clouds and aerosols from the stratosphere to the ground. It was launched on 28 April 2006 on a Sun-synchronous orbit at $705 \mathrm{~km}$ height with 15 orbits per day. CALIPSO hosts the CALIOP lidar that operates at 532 and $1064 \mathrm{~nm}$ wavelengths, and a passive remote-sensing instrument working in the infrared bandwidth (IIR, Imaging Infrared Radiometer) and the visible range (WFC, Wide Field Camera). Analysis is limited to CALIOP level 2 observations of backscatter vertical profiles to discriminate between clouds and aerosol and to extract local information about their vertical and spatial extent, mean depolarization and backscatter coefficient; optical properties provide a primary discrimination between six different classes of aerosol and eight types of clouds. Major concerns about the quality of CALIOP data have to do with uncertainties due to the finite detection sensitivity of the CALIOP instrument, to the assumption of lidar ratios, and misclassification of features.

Comparison of monthly regionally-averaged aerosol extinction profiles over the period 2007-2009 from CALIOP Version 3 data with the AeroCom model found important improvements in the data but still expressed doubts on the choice of the detection limits and on the general accuracy of aerosol extinction data (Koffi et al., 2012). Schuster et al. (2012), carrying out a comparison between CALIOP column aerosol optical depths at $0.532 \mu \mathrm{m}$ with measurements in 147 worldwide AERONET (Aerosol Robotic Network) sites, show that statistically significant differences between the data sets are caused mainly by bias in classification of dust (desert aerosol) subtypes, indicating in particular the possibility that the assumed lidar ratio $(40 \mathrm{sr})$ for the CALIOP dust retrievals is too low. Omar et al. (2013), comparing CALIOP $532 \mathrm{~nm}$ level 2 AOD with co-located AERONET $500 \mathrm{~nm}$ AOD, noted that CALIOP generally underestimates AOD when it is on the order of 0.05 or lower, probably because of a poor detection of weak aerosol layers. Winker et al. (2013), comparing long-term averages from 
a few AERONET sites in the remote Pacific Ocean with regional monthly-mean CALIOP AOD, show instead that monthly-mean gridded AOD and aerosol extinction profiles appear to be realistic and representative; but again, when aerosol loading decreases, representativeness of the CALIOP observations becomes problematic: in particular, magnitudes of aerosol extinction retrieved in the upper troposphere may be underestimated. These limitations should be kept in mind while interpreting the results of CALIOP data analysis.

The analysis focuses on aerosol layers defined in CALIOP data as desert aerosol (dust), particles produced by combustion and composed mainly by soot and organic carbon (smoke), and a mix between dust and smoke (polluted dust) which appears from this analysis to be the main typologies of particulate over the region. Statistics are based on the frequencies of occurrence of each class, estimated as the ratio between the number of observations of at least one layer of a particular class of aerosol and the total number of satellite tracks, within a 3-dimensional grid during a determined time period. The temporal and horizontal resolution of the grid is limited by the repetition rate of the instrument. For a $3^{\circ} \times 3^{\circ}$ horizontal resolution CALIOP provides on average 8 to 10 profiles per month. Observations are therefore cumulated over 3 months to have a trade-off between the possibility to have a seasonal coverage and a sufficient number of observations to ensure a reasonable representativeness of each bin. This resolution is compatible to the analysis presented in Liu et al. (2008) where data are accumulated over a $2^{\circ} \times 2^{\circ}$ grid. Profiles containing opaque convective or cumulus clouds diagnosed by CALIOP were removed to avoid underestimation in the frequencies of occurrence. The frequency of cloudy profiles on the region, over a total of around 65000 profiles per month, is generally less than $25 \%$ with peaks of $30 \%$ in July and August. The frequency of occurrence is computed on a geographical rectangle surrounding the Himalayan Plateau $\left(20-45^{\circ} \mathrm{N}, 60-120^{\circ} \mathrm{E}\right)$ for $2 \mathrm{~km}$-thick layers, in the 0 to $8 \mathrm{~km}$ height range.

The influence of aerosol sources is investigated with transport analysis. Back trajectories are originated from a regular latitude-longitude grid with an horizontal resolution of $0.5^{\circ}$, extending over the same region of the observation analysis (see Figs. 1-4). The trajectories are calculated daily from pressure levels of $700 \mathrm{hPa}$ (roughly representative of the 2$4 \mathrm{~km}$ layer) and $500 \mathrm{hPa}$ (corresponding to the $4-6 \mathrm{~km}$ layer). Trajectories are run backward in time for 10 days to resolve medium-range transport patterns, being compatible with the average lifetime of aerosol in the atmosphere and with a reasonable limit on the uncertainty on air parcels position (Stohl, 1998). In any case, the use of clusters of trajectories and of a time interval of 3 months helps to reduce the uncertainties on the statistical analysis. Meteorological input comes from the ECMWF (European Centre for MediumRange Weather Forecasts, http://www.ecmwf.int/) with $6 \mathrm{~h}$ steps and $0.5^{\circ}$ resolution. Due to known limits of kinematic trajectory calculations in the turbulent layer, the analysis is limited to the transport above the planetary boundary layer (PBL). So, an approach similar to Bergman et al. (2013) was chosen: sources are identified as the points where the trajectories crossed irreversibly the PBL height, considering the rough approximation that aerosol are uniformly mixed below that layer. The PBL height was estimated accordingly as an idealized terrain-following surface:

$P_{\mathrm{PBL}}=\frac{0.15 * p^{3}}{p_{0}^{2}}$

where $p_{0}$ is the mean sea-level pressure. The localization of desert areas was made by means of ground cover maps from the US Geological Survey (USGS) Land Cover Institute (LCI) (http://landcover.usgs.gov). Sources of smoke aerosol are identified with the help of the MACCity biomass burning emissions data set (http://accent.aero.jussieu.fr/) (Granier et al., 2011; Diehl et al., 2012; Lamarque et al., 2010; van der Werf et al., 2006). Biomass burning and anthropogenic emissions of black carbon are cumulated to take into account two main sources of the particles that are classified as smoke based on the observed optical parameters. A minimum threshold of $5 \times 10^{-12} \mathrm{~kg} \mathrm{~m}^{-2} \mathrm{~s}^{-1}$ is applied to select the more active emission regions. On average, the geographical distribution during the pre-monsoon phase (not reported here) shows the presence of two main macro areas in northern India and continental China for anthropogenic emissions, while biomass burning is less intense and more variable in location with frequent production in southeast Asia. A frequency of potential sources was estimated, analogously to CALIOP aerosol observations, as the ratio between the number of back trajectories crossing a PBL over a specific source and the number of total back trajectories for each bin. The result represents a spatial distribution directly comparable with those obtained from CALIOP data.

\section{Aerosol variability derived from CALIOP}

The following two subsections present the results of the CALIOP data analysis. The first subsection investigates the seasonal variability of the spatial distribution of the more frequently observed classes of aerosol over four vertical layers $(0-2 \mathrm{~km}, 2-4 \mathrm{~km}, 4-6 \mathrm{~km}, 6-8 \mathrm{~km})$. In the second subsection the analysis is focused over different subregions (shown in the bottom right of Fig. 1). Temporal series of monthly frequency of occurrence of the classes of aerosol are analyzed over different layers to study the interannual variability on the aerosol presence over the region.

\subsection{Seasonal variability}

Spatial distribution of frequency of occurrence for each aerosol class and for each vertical layer is reported in Figs. 1-4 for the winter (DJF), spring (pre-monsoon, MAM), summer (monsoon, JJA) and fall (SON) seasons. Aerosol 

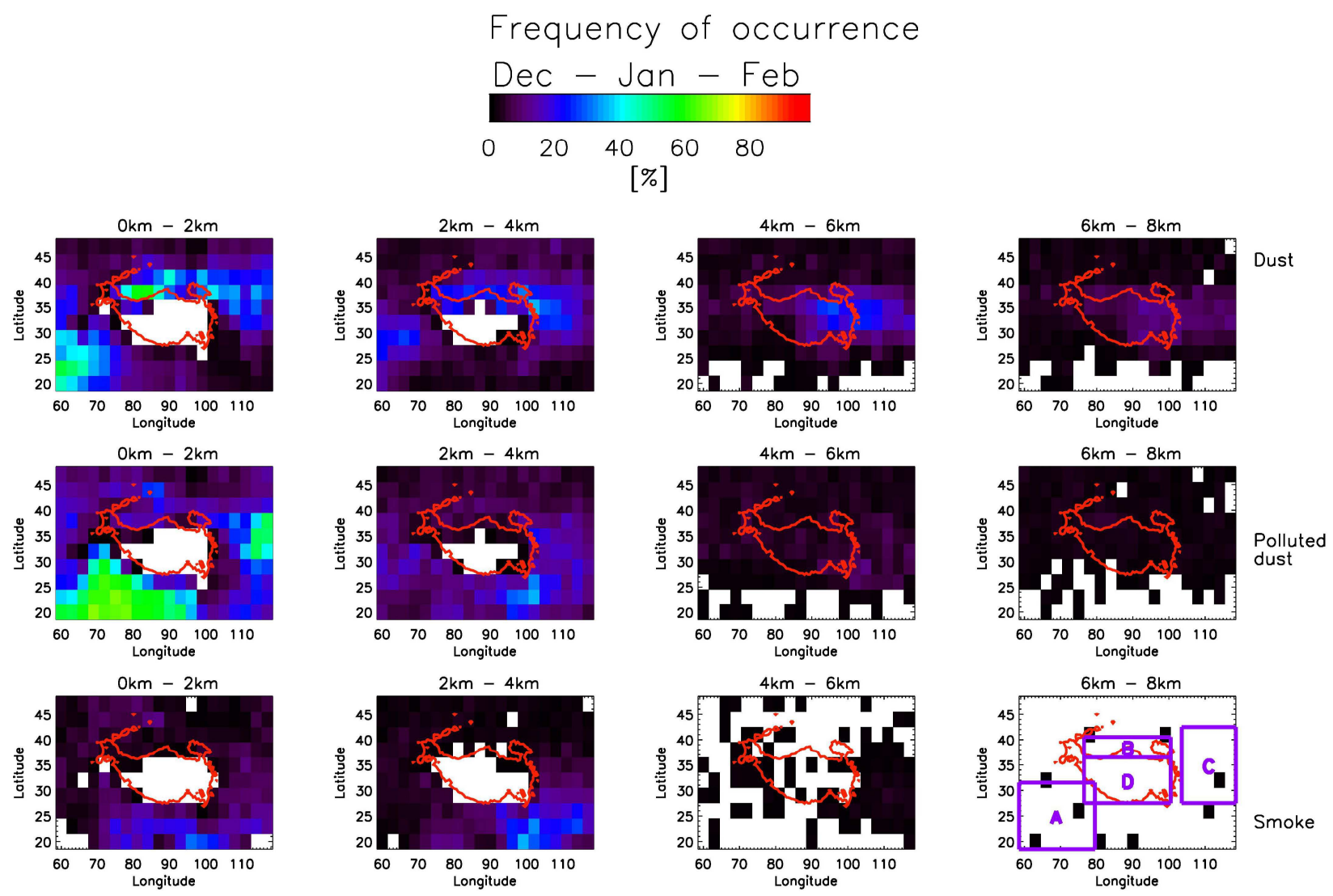

Fig. 1. Aerosol frequency of occurrence for the DJF season. Different aerosol types (dust, polluted dust, smoke) are reported from top to bottom. Different vertical layers are reported from left to right. White shades indicate absence of aerosol layers. In the right bottom the violet boxes highlight the four subregions that will be considered in the interannual analysis (see Sect. 3.2)

observations are cumulated over the 2007-2010 years. In DJF dust occurrences are found southwest and northeast of the plateau in the lower layers with frequencies up to $50 \%$, with a net decrease found in the higher layers where, over the eastern part of the plateau, frequencies can reach $20 \%$. MAM is, on average, richer in dust, forming a similar structure surrounding the plateau in the lower layers with higher frequencies (up to $80 \%$ ). In the higher layers the frequency increases above the plateau with respect to DJF, with values that can reach up to $40 \%$ at $4-6 \mathrm{~km}$ and $30 \%$ at $6-8 \mathrm{~km}$ height. During JJA the distribution is more localized on the western side of the Himalaya. The branch located north of the plateau appears to be weaker and does not reach eastern China. There is still a relatively important amount of dust that reaches the 6-8 km layer (more than $15 \%$ ). In SON the spatial distribution of dust remains largely similar to those observed in JJA, with overall lower values of frequency. Nevertheless, bias may arise due to the filtering of convective clouds in southern India during the Monsoon season, when the scarcity of cloud-free measurements can affect the representativeness of the statistics. As expected, polluted dust shares the distribution of both smoke and dust. A closer look at the CALIPSO backscatter and depolarization profiles for
May 2007 (not reported) shows that polluted dust is identified when optical parameters lie in an intermediate range between smoke and dust, thus suggesting that an external mixing of the two species is present without a clear predominance of one species over another. Polluted dust in MAM is mostly observed in northern India, between the main source regions of dust and carbonaceous particles (respectively Thar and Bay of Bengal). In JJA, at low heights, it is distributed nearly homogeneously over India, China and northwest of the plateau with a frequency around $20 \%$. In SON, the frequencies over India increase while decreasing on the northwest side. In DJF, for the first $2 \mathrm{~km}$, the frequencies over India reach a maximum of $70 \%$, while for the heights between 2 and $4 \mathrm{~km}$ the highest frequencies are localized southeast of the plateau. Above the Himalayas there is a nearly steady frequency of slightly less than $10 \%$, with a maximum in JJA.

The results are compared with Liu et al. (2008), where dust is identified as layers with an average aerosol depolarization greater than 0.06 , and the aerosol occurrence was determined as the fraction of profiles containing dust with respect to the total number, using cloud-free nighttime data. Although the levels of processing of the database and the time coverage are different, there is a good agreement on the spatial distribution 


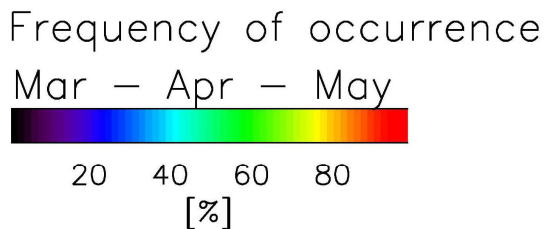

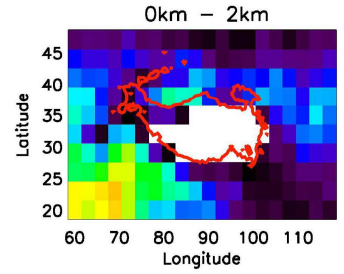

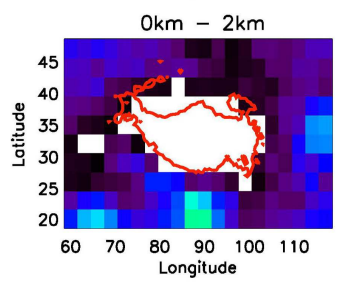

$\mathrm{Okm}-2 \mathrm{~km}$

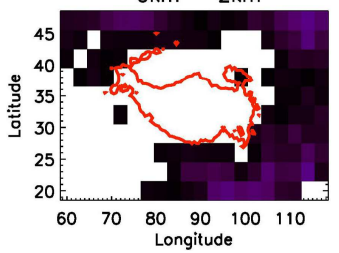

$2 k m-4 k m$

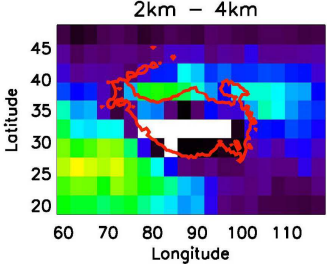

$2 \mathrm{~km}-4 \mathrm{~km}$

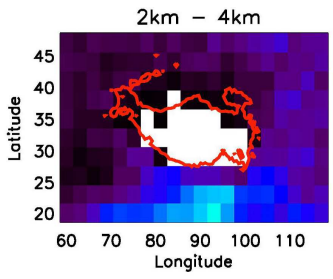

$2 k m-4 k m$

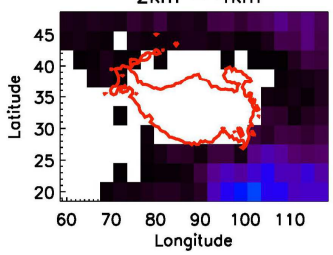

$4 k m-6 k m$

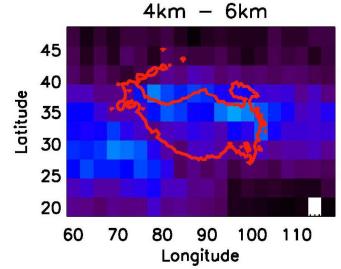

$4 k m-6 k m$
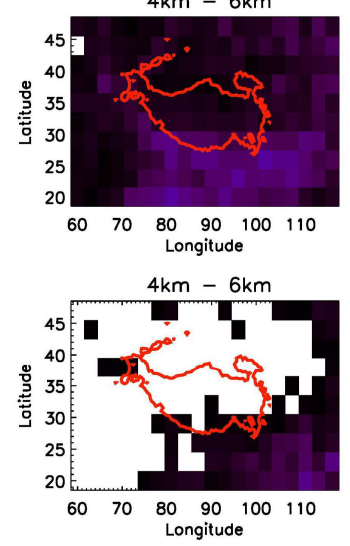

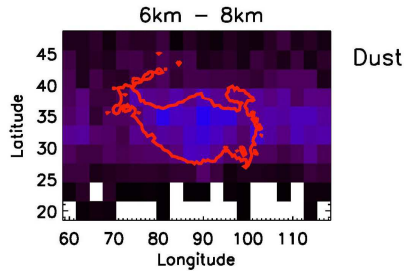

$6 \mathrm{~km}-8 \mathrm{~km}$
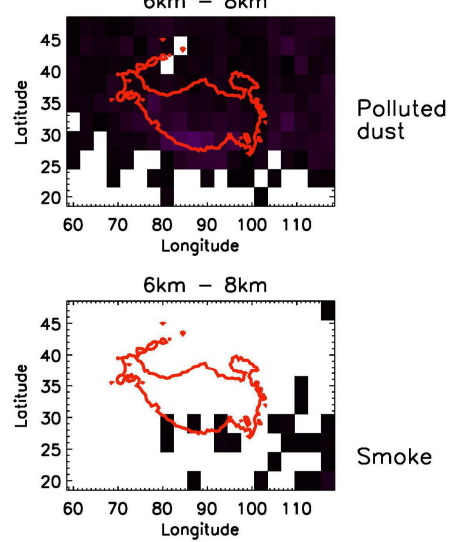

Fig. 2. As Fig. 1 but for MAM season.

(see plate 2 in Liu et al., 2008). On the other hand, frequencies found here are in general lower than Liu et al. (2008) and largest differences are found for the bottom layer. Discrepancy may be likely attributed to the use of different data and diagnostic applied since level 2 data used here identify the presence of dust with a method that combines an assessment of volume depolarization (that has to be greater than 0.2 ) and the underlying ground surface type. Moreover level 2 data discriminate between dust and polluted dust, the latter being characterized by a volume depolarization ranging from 0.075 to 0.2 . This implies that frequencies reported in Liu et al. (2008) may have a positive bias with respect to the ones presented here. Moreover, orography reduces the vertical thickness of the lowermost layers, inducing a possible negative bias on the statistics applied here. This is for example visible in Fig. 2 as a lower frequency area in the $0-2 \mathrm{~km}$ layer (with respect to the $2-4 \mathrm{~km}$ one) around the Thar mountains $\left(65^{\circ} \mathrm{E} 32^{\circ} \mathrm{N}\right)$, where orography is relevant.

Smoke has its maximum values of occurrence in JJA. In this season, for the first $4 \mathrm{~km}$ atmospheric column, higher frequencies occur east of the plateau, while, during the following season (SON), moves on the south China and northeast India. The pattern remains the same for DJF and MAM but with a frequencies decrease.
In general, dust is the principal typology of aerosol with two distinct main regions (SW and NE plateau sides) and also relevant presence above the Himalayas. Smoke on the plateau is limited to JJA and SON, in both cases with lower frequencies with respect to dust.

\subsection{Interannual variability}

Interannual differences are estimated for 4 selected regions: (A) Pakistan and Western India $\left(20-33^{\circ} \mathrm{N}, 60-81^{\circ} \mathrm{E}\right)$; (B) north slopes of the plateau $\left(38-42^{\circ} \mathrm{N}, 78-102^{\circ} \mathrm{E}\right)$; (C) eastern China $\left(29-44^{\circ} \mathrm{N}, 105-120^{\circ} \mathrm{E}\right)$; and (D) Himalayan Plateau (29-38 $\left.{ }^{\circ} \mathrm{N}, 78-102^{\circ} \mathrm{E}\right)$. (A) and (B) are two distinct regions rich in dust and polluted dust, while (C) presents again high frequencies of both dust and smoke. (D) is needed to evaluate the presence of airborne particles above the plateau. The different regions are marked on a map in Fig. 1. The frequency time series are reported in Fig. 5 and data are now accumulated with a monthly frequency over a 3-monthwide time window. The time series are estimated for the same layers as Figs. 1-4 but not reported for the regions where orography substantially reduces the layer thickness to avoid a bias on the aerosol frequency of occurrence $(0-2 \mathrm{~km}$ in the northern plateau and China and $0-4 \mathrm{~km}$ on the plateau). 

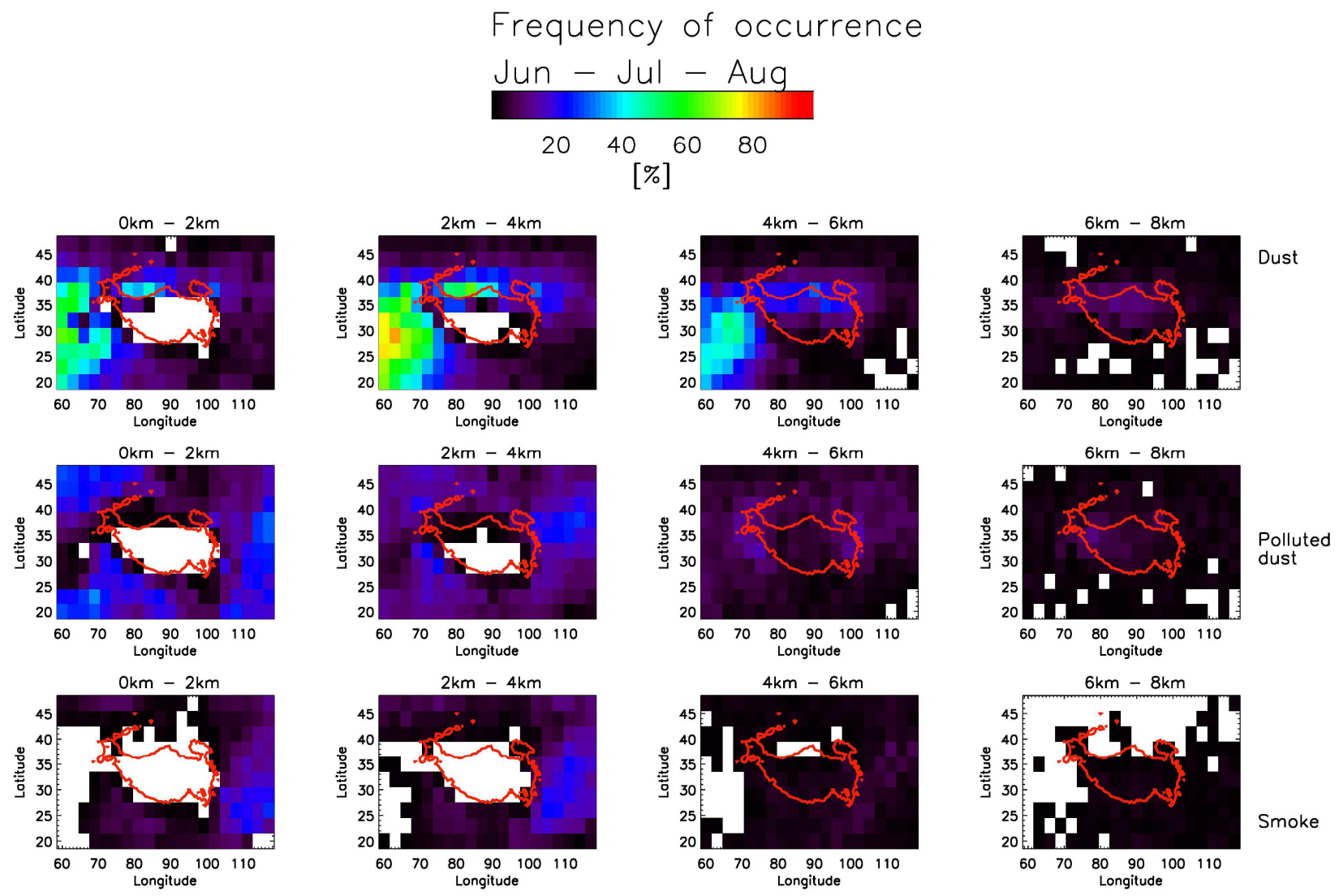

Fig. 3. As Fig. 1 but for JJA season.

In region (A) dust has, at low altitudes, a marked semiannual cycle with two maxima around March and September (the latter is less pronounced). Minima in frequency of occurrence are found in June and November. The presence of an annual cycle at $4-6 \mathrm{~km}$ suggests that June minimum in the lower layers can be linked to a mechanical wet deposition during the summer monsoon. Above $6 \mathrm{~km}$ there is a significant amount of dust (around 10\%) in spring and summer. It is possible to note a clear difference between 20072008 and 2009-2010. In these last two years, sensibly lower occurrence of dust aerosol is observed in the lower layers, while highest values are recorded in spring 2008. Gautam et al. (2009) observe a higher dust load in MAM 2008 with respect to 2007, attributing the differences to the increased 2007 winter rainfall in the Thar desert region that likely reduced the intensity of the dust source. TRMM (Tropical Rainfall Measurement Mission) monthly mean data available from GPCP (Global Precipitation Climatology Project) show a strong positive precipitation anomaly in spring 2007, while the years 2009-2010 appear to be drier (available from the GPCP website and not shown here). Our results are therefore consistent with the 2008 maximum aerosol loading of Gautam et al. (2009) but cannot be conclusive on the correlation between low aerosol occurrence and positive anomaly in spring precipitation.
As shown in Fig. 5, India is also the region with highest occurrence of polluted dust reaching values over $30 \%$ between October and February in the first atmospheric layer. Polluted dust occurrence has a marked seasonal variability with a minimum in spring and a maximum in autumn. At higher altitudes the frequencies are lower and the annual cycle is less pronounced. Smoke also presents a well-defined annual periodicity with almost no occurrence in spring, a gradual increase until a maximum of about $6 \%$ in NovemberDecember and then a rapid decrease. Presence of smoke above $4 \mathrm{~km}$ is marginal. Eastern China (B) is the richest in smoke air with the highest values (on average $10 \%$ of occurrence) in JJA and a similar frequency in the first two layers (even somewhat higher for the 2-4 km). The lower occurrences are observed in March and April. Dust has a maximum in spring as also observed from ground-based AERONET data (Eck et al., 2005). Polluted dust has higher frequencies and an annual cycle close to smoke particles, likely contributing to the maximum optical depth observed in summer by the same authors. The northern plateau (C) sees a dominance of dust particles being far from the more intense source regions. The $2-4 \mathrm{~km}$ layer shows again a semiannual cycle that is less visible at higher altitudes. Polluted dust and smoke have sensibly lower frequencies of occurrence (a maximum of 10 and $2 \%$, respectively) with respect to the (A) and (B) regions with 


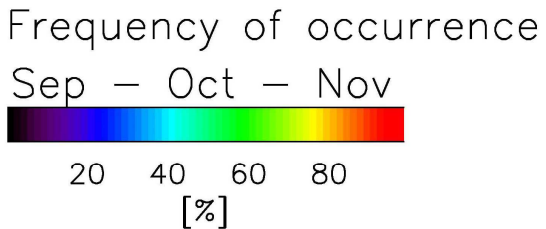

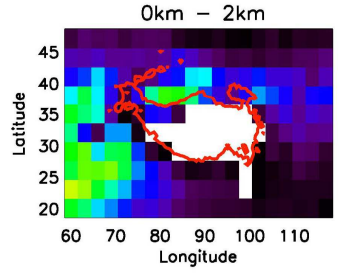

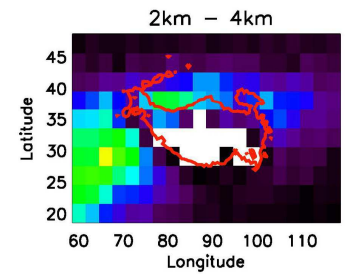

$\mathrm{Okm}-2 \mathrm{~km}$

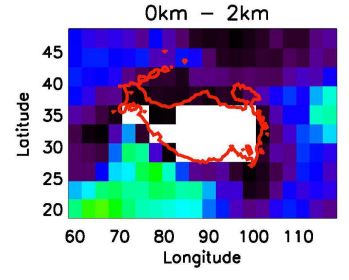

$\mathrm{Okm}-2 \mathrm{~km}$

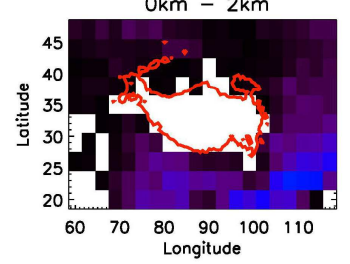

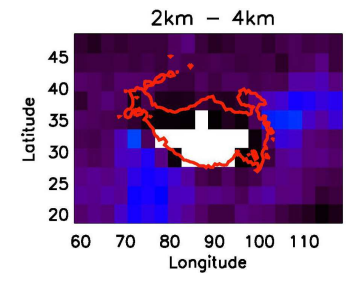

$2 \mathrm{~km}-4 \mathrm{~km}$

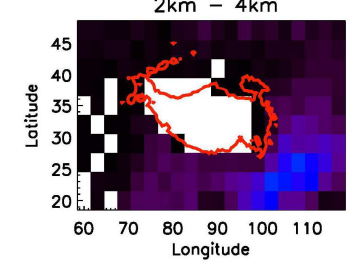

$4 k m-6 k m$

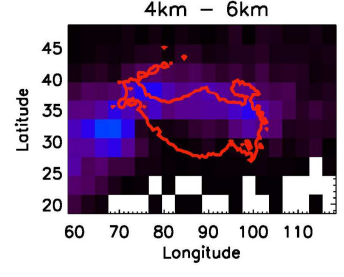

$4 k m-6 k m$
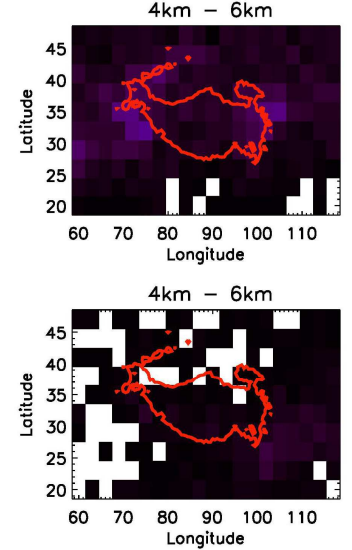

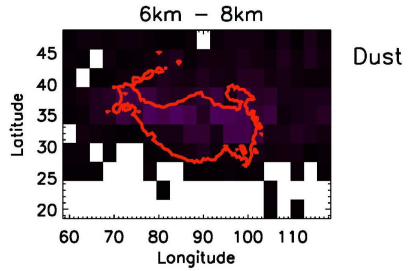

$6 k m-8 k m$
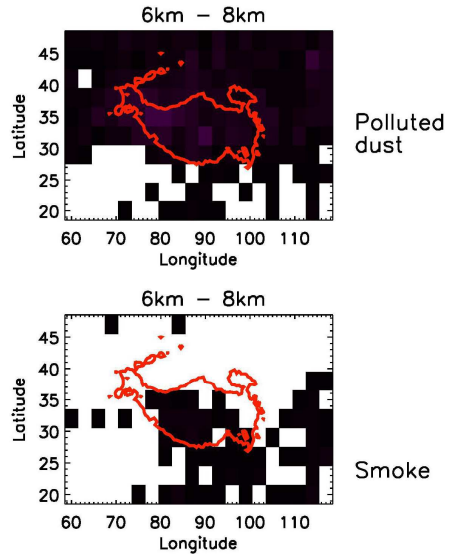

Fig. 4. As Fig. 1 but for SON season.

a less clear seasonal variability. The Himalayan Plateau (D), despite the lower occurrence, has a marked annual cycle for dust and smoke with maxima in spring and summer, respectively. Again, 2007 and 2008 are characterized by a higher occurrence of atmospheric particulate.

Overall, as seen before, dust is the dominant type of aerosol on the Himalayan plateau and the surrounding regions. Nevertheless, smoke aerosol and polluted dust have a relevant presence in China and India, showing a similar annual cycle that is out of phase with respect to the one followed by dust.

\section{Aerosol sources and atmospheric transport analysis}

The objective is now to identify the possible sources contributing to the observed aerosol spatial distribution and to quantify them as a probability to originate from the PBL above a determined source region.To better explain the transport patterns around the Himalayan region we report in Fig. 6 the back-trajectory analysis for a small source region east of the plateau, for the month of April 2010. The back trajectories originated both at 700 and $500 \mathrm{hPa}$. In Fig. 6 source regions are colored in yellow for dust and grey for smoke. The violet box represents the area of release of the back trajec- tories. The black contour represents the area where $99 \%$ of the positions of the trajectory particles are found during the 10 days. Light-blue crosses are the irreversible PBL crossing points. The red contour identifies the presence of the Himalayan Plateau. From the figure it is possible to notice that air masses come from two distinct flows surrounding the plateau. The northern one intercepts the potential dust source region from the Taklamakan and Gobi deserts and was identified by Liu et al. (2008) as an airborne dust corridor. The southern one encounters mixed source regions located in West and northern India (Shrestha and Barros, 2010). It appears that at $700 \mathrm{hPa}$ air parcels exit the PBL mostly locally (light-blue points in Fig. 6, left panel) or close to the area where back trajectories are originated, with a smaller contribution from distant sources. It should be noted that a fraction of air parcels apparently originate from the PBL above the eastern flank of the plateau, leading to a possible overestimate of the PBL contribution. The analysis is now carried out on the back trajectories leaving from the source region that extends over the same area of the observations (highlighted by the black box in Fig. 7) for the dusty spring season (MAM) for 2007-2010. Based on the PBL exit point locations, the main black carbon emission regions are located in eastern China and northern India, where they seem to have a strong influence on the amount of pollution 

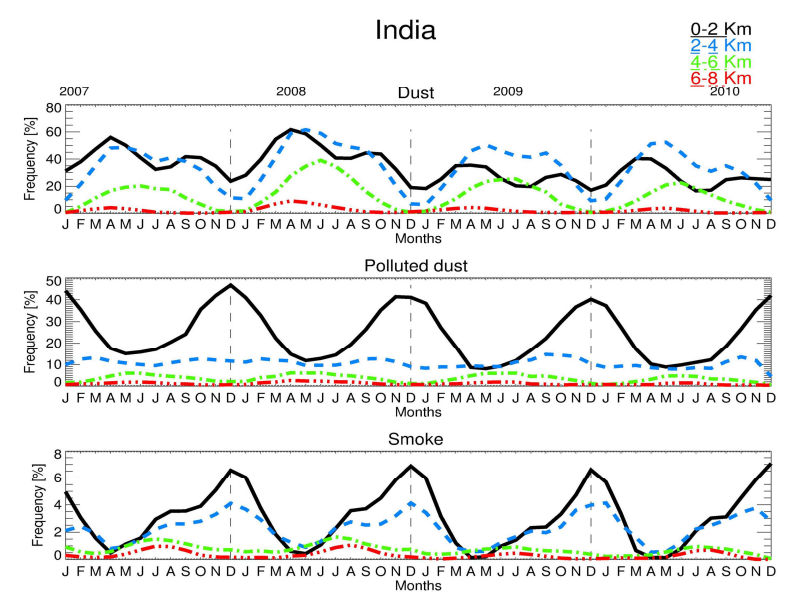

North Plateau
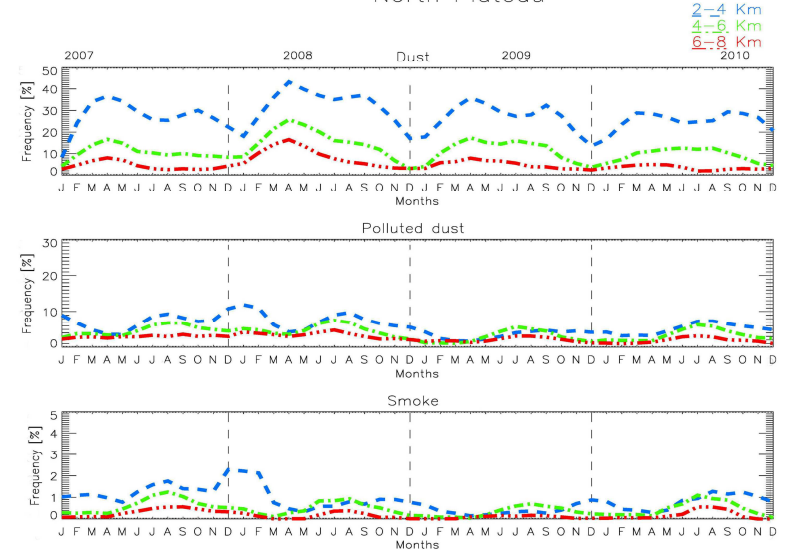

A)
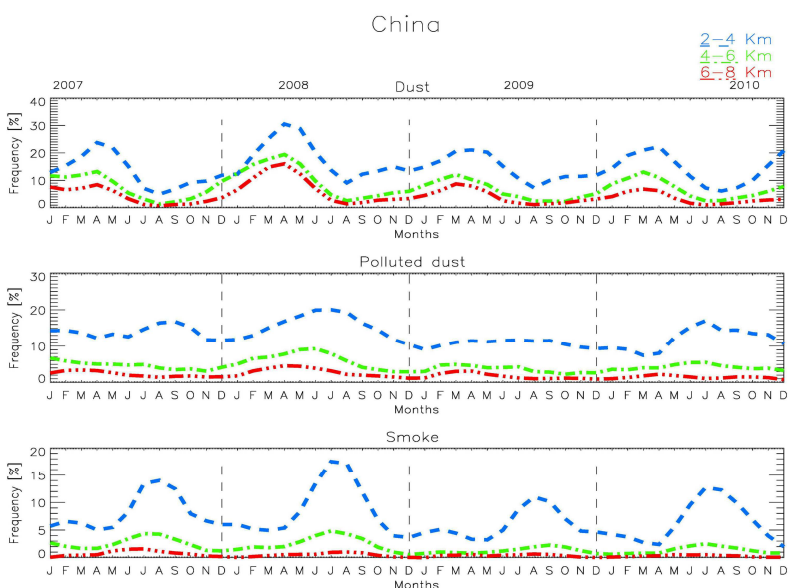

C)

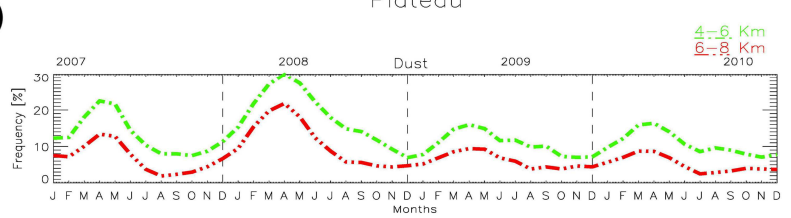

D)
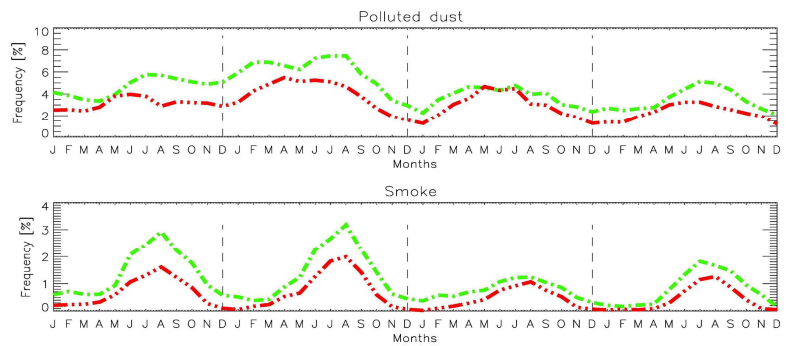

B)

Fig. 5. Frequency of occurrence for dust, polluted dust and smoke for the (A) Pakistan and Western India $\left(20-33^{\circ} \mathrm{N}, 60-81^{\circ} \mathrm{E}\right)$; $(\mathbf{B})$ north slopes of the plateau $\left(38-42^{\circ} \mathrm{N}, 78-102^{\circ} \mathrm{E}\right)$; (C) eastern China $\left(29-44^{\circ} \mathrm{N}, 105-120^{\circ} \mathrm{E}\right)$; and (D) Himalayan Plateau $\left(29-38^{\circ} \mathrm{N}, 78-102^{\circ} \mathrm{E}\right)$ for the years 2007-2010. Different lines report the vertical layers 0-2 km (black), 2-4 km (blue dashed), 4-6 km (green), and 6-8 km (red). Readers may note the different vertical scales.
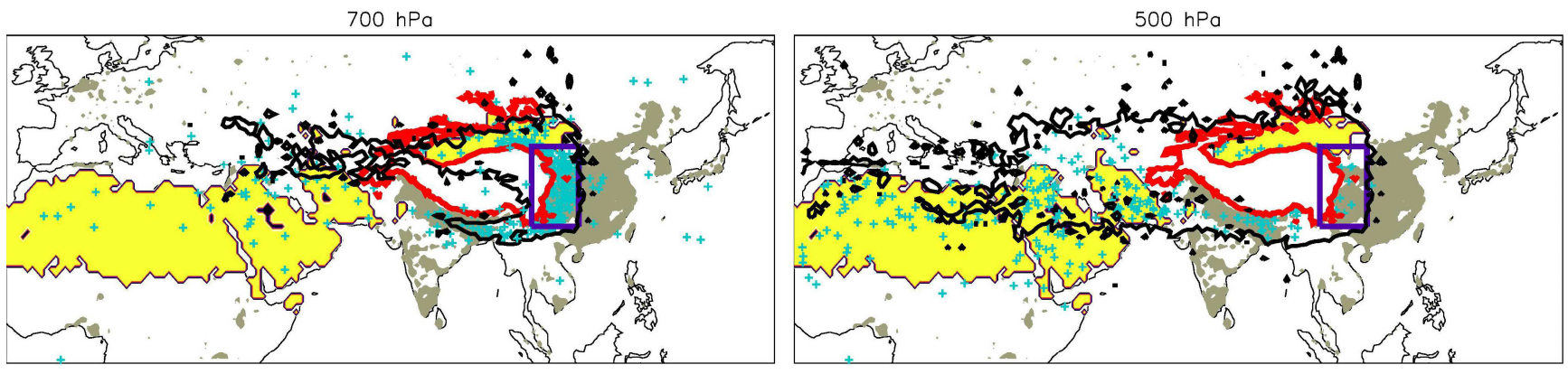

Fig. 6. Back trajectories originating east of the plateau at $700 \mathrm{hPa}$ (left) and $500 \mathrm{hPa}$ (right) for April 2010. Violet box indicates the starting point area of the back trajectories. Yellow areas are the dust regions considered as potential sources. Grey areas are total black carbon emissions greater than the threshold mentioned in the text. Black contour surrounds the regions where around $99 \%$ of the back trajectory particles are found, while the light-blue points are the irreversible PBL crossing points. Red contour reports the $700 \mathrm{hPa}$ level to identify the presence of the Himalayan Plateau. 

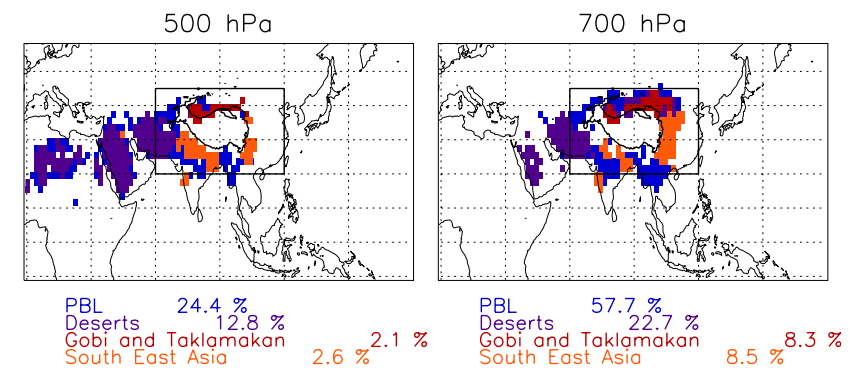

Fig. 7. Geographical distribution of PBL exit points for back trajectories at $500 \mathrm{hPa}$ (left) and $700 \mathrm{hPa}$ (right). Different sources are plotted with the color table reported in the figure together with its relative contribution. Black box indicates the starting point area of the back trajectories. Analysis includes the 2007-2010 spring seasons.

in the east side of the plateau, with a large number of PBL crossing points over these regions. Similarly dust is principally originated from deserts north of the plateau and, to a lesser extent, more distant sources. At $500 \mathrm{hPa}$, trajectories indicate that distant sources can have a more important role with respect to $700 \mathrm{hPa}$ with a larger amount of air parcel conveyed by the airborne corridor. PBL exit points are now mostly located above dust sources in the central Sahara, Arabian Peninsula and Iran-Afghanistan, while black carbon emissions are intercepted mainly above northern India by the southern branch. Fig. 7 reports the locations where air parcels ending in the Himalayan region leave irreversibly the PBL. At $700 \mathrm{hPa}$ (roughly representative of the $2-4 \mathrm{~km}$ layer) more than $57 \%$ of the air masses come from the PBL, with a dominance of sources included in the larger Himalayan region. Desert sources account for nearly $23 \%$, with more than one third (around $8 \%$ ) coming from arid areas north of the plateau (Gobi and Taklamakan) and the remaining fraction originating from Thar, Iranian and Arabian deserts. Trajectories coming from biomass burning sources contribute up to $8.5 \%$ and are distributed over the main region of emissions: eastern China and, to a lesser extent, northern India. At $500 \mathrm{hPa}(4-6 \mathrm{~km})$ the trajectories coming from PBL are $24.4 \%$ of the total with a different spatial distribution: dust is linked to a longer-range transport, coming now from the Arabian Peninsula and the Sahara. Desert dust trajectories now contribute up to half of the total PBL air $(12.8 \%$ of the total), with a much smaller fraction (2.1\% of the total) coming from the Gobi and Taklamakan deserts. Air masses from biomass burning area are also a smaller fraction $(2.6 \%)$ with respect to the $700 \mathrm{hPa}$ layer. The PBL crossing points are located over the main emissions regions, but, with respect to the $700 \mathrm{hPa}$ layer, northern India sources span over a larger area. The same estimates were done for each year from 2007 to 2010, and it appears that there are no significant interannual variations in the PBL source fractions. The values reported in Fig. 7 may be directly compared with the regional mean of the occurrence frequency derived from CALIPSO data in Fig. 2. This is based on the assumption that the probability to observe the presence of an aerosol layer (that can be thin) can be quantitatively explained by the probability of transport from aerosol sources given by the Lagrangian analysis. Despite the fact that this assumption can be straightforward, significant differences may occur, besides the error of the Lagrangian transport itself (Stohl et al., 1998), from several factors of uncertainty. Circulation given by the atmospheric analysis is not representative of mesoscale processes that influence aerosol distribution (i.e., forced uplift, local convection); the assumption of pure passive transport neglects the removal processes; the source attribution does not take into account the uncertainty of the emissions and their degree of vertical mixing inside the PBL that may affect the effective dust or biomass burning load at the top of it. In addition, observed polluted dust cannot be partitioned into smoke and dust aerosol since both sources may contribute to its formation (this is visible in Fig. 2 above northern India). Therefore, in the following analysis, it is decided to only consider pure dust and smoke in order to avoid multiple countings and hence an overestimate of the observed frequency of layer detection. CALIPSO at $700 \mathrm{hPa}$ $(2-4 \mathrm{~km})$ gives a dust occurrence frequency of $26 \%$ and a smoke occurrence frequency of about $4 \%$ (as well as a polluted dust occurrence frequency of $10 \%$ ). Despite the uncertainties mentioned above, such values are in satisfactory agreement with those derived from the trajectories. Similarly, at $500 \mathrm{hPa}(4-6 \mathrm{~km})$ the observed frequencies of occurrence (dust $14.3 \%$ and smoke $1.5 \%$ ) are comparable to those derived from the Lagrangian analysis. Figure 8 reports the fraction of back trajectories originating from the whole PBL and the source regions identified before (deserts and carbonaceous emissions in south Asia). Their spatial distribution may be compared directly with the observations reported in Fig. 2. At $700 \mathrm{hPa}$ particles coming from the PBL show a nearly homogeneous distribution around the plateau with a maximum in the southeast side. This area presents modest orography and therefore a higher PBL top (in geographical coordinates) with respect to the surrounding regions. Consequently a back trajectory leaving from that area has a greater probability to have a close encounter with the PBL, leading to higher frequencies in its geographical distribution. Moreover, the overestimate of the PBL air east of the plateau may come from a flux originating on the eastern flank of the Himalaya (see discussion of Fig. 6). PBL exit is co-located with a high emissive region, leading to a likely overestimate of smoke maximum occurrence. Besides this anomaly, smoke frequencies are substantially similar to those derived from CALIPSO (around 20\%). Trajectory analysis shows that smoke emissions mainly impact a region southeast of the plateau (between northern India and eastern China) that is identified in the observations, the latter showing also a relevant region south of the Himalaya where emissive fluxes are negligible (as visible in Fig. 6). Again, this difference may be attributed to an incorrect transport in the PBL and/or to the emissions 

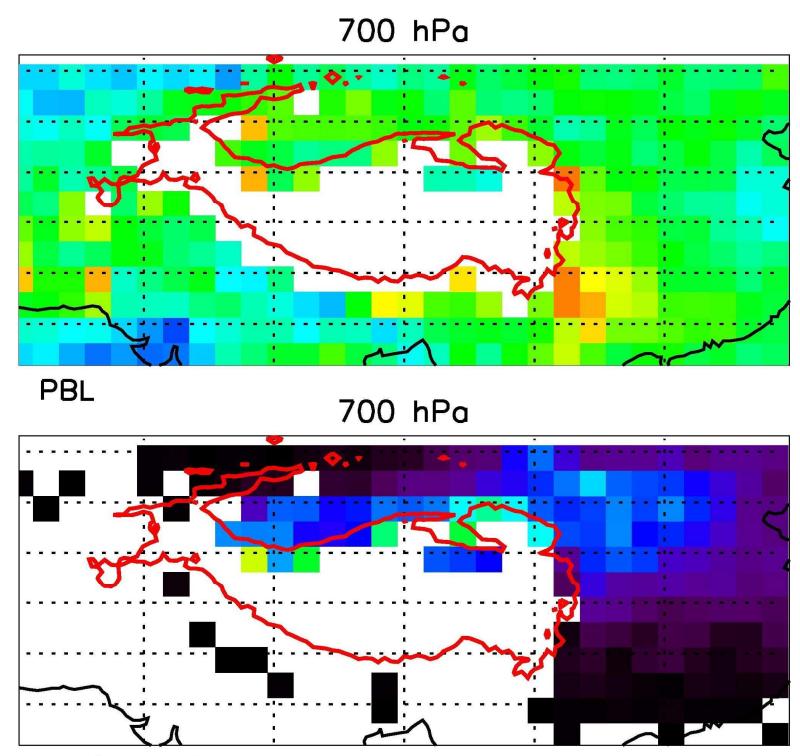

Gobi and Taklamakan
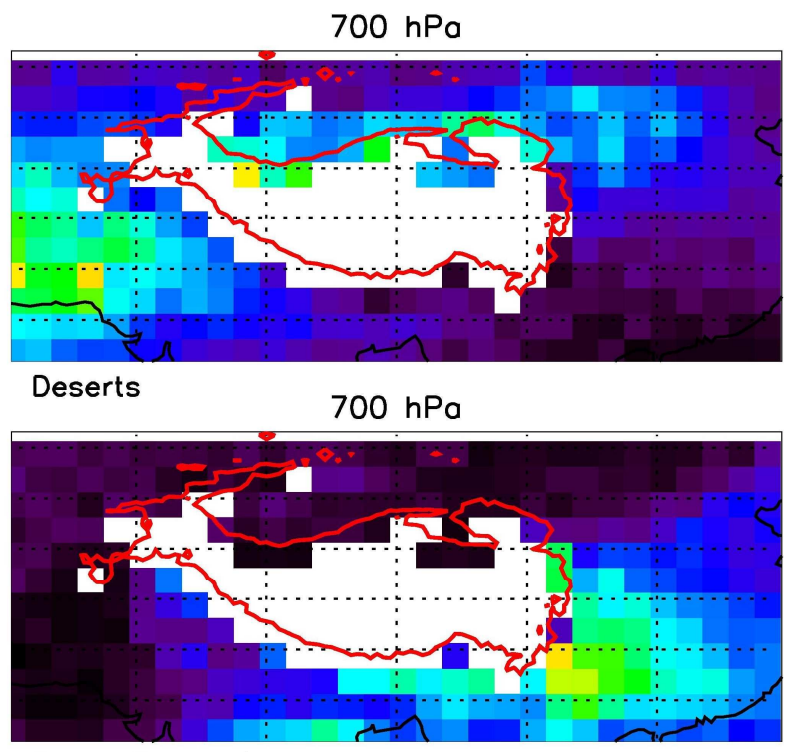

South East Asia

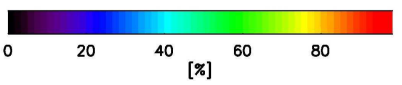

Fig. 8. Frequency of occurrence of air masses at $750 \mathrm{hPa}$ coming from different PBL sources (top left panel: whole PBL, as defined in the text; top right: PBL above deserts; bottom left: PBL above deserts north of the plateau; bottom right: PBL above carbon aerosol emissive regions). Color scale is the same as Figs. 1-4.
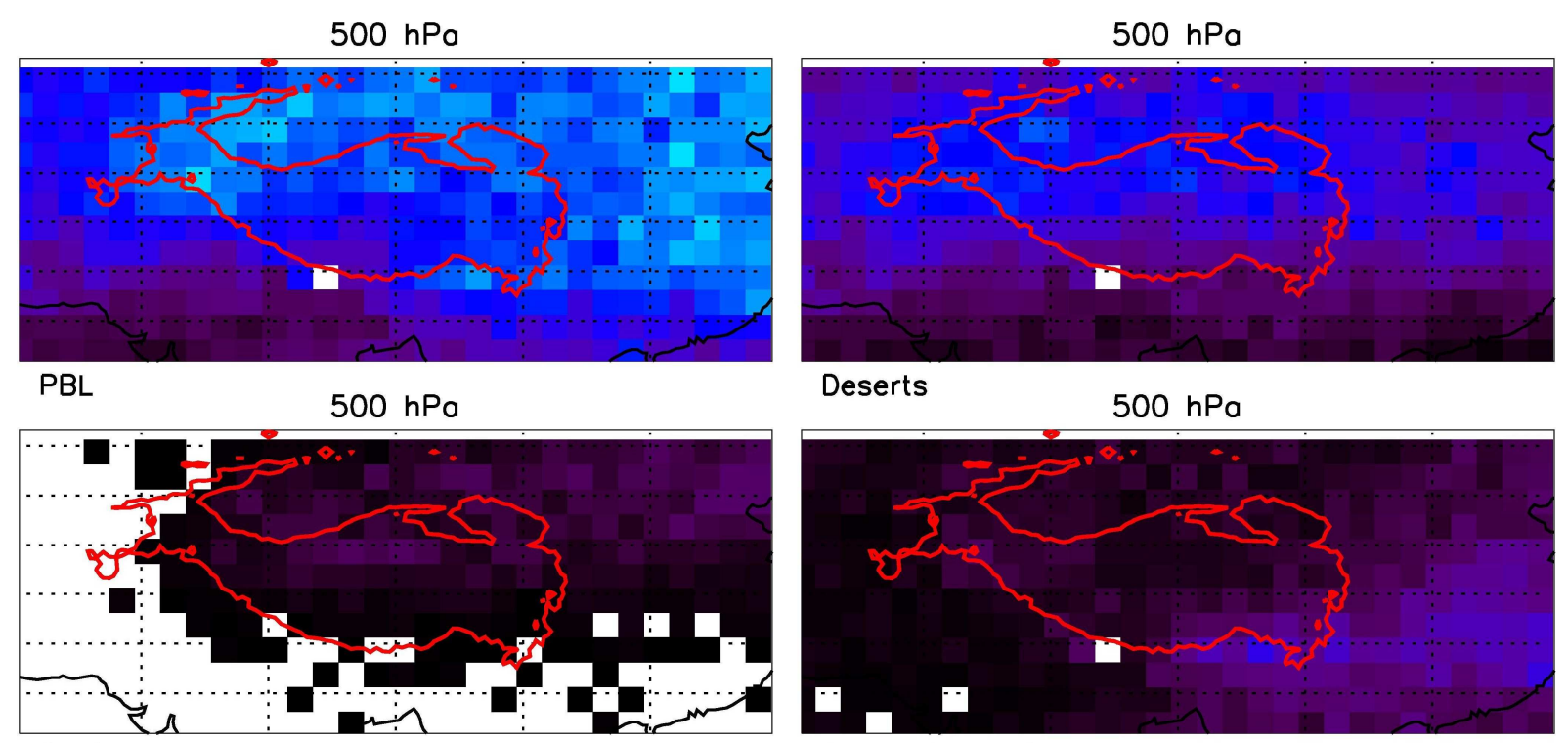

Gobi and Taklamakan

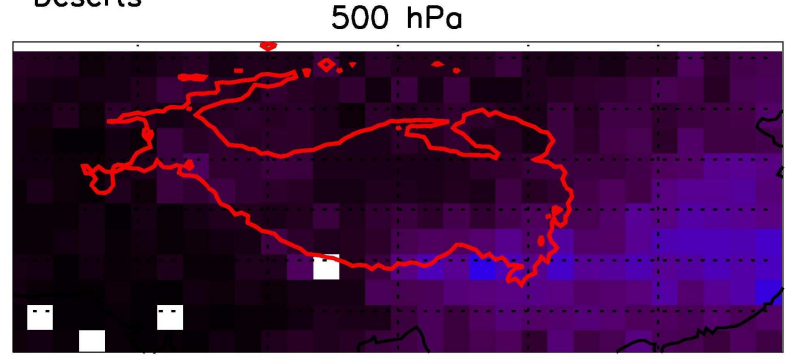

South East Asia

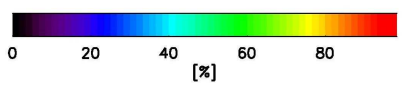

Fig. 9. As Fig. 8 but for the $500 \mathrm{hPa}$ level. 
used, including anthropogenic biomass and biomass burning, while the smoke identified in CALIPSO may comprehend a larger typology of pollutants. The spatial distribution of observed dust aerosol is correctly reproduced by the transport diagnostics. The frequency of occurrence is also generally well represented, with values slightly smaller than the observed ones. The dusty region north of the plateau is correctly identified and appears to be mainly linked to aerosol transport from the Gobi and Taklamakan deserts. The western pattern of dust comes from longer-range transport, with a relevant contribution from the Sahara and Arabian Peninsula. Satellite observations show a more pronounced penetration of dusty layers southeast of the plateau. At $500 \mathrm{hPa}$ (Fig. 9), the trajectories seem to have less agreement with the observations. It is necessary to note that ECMWF analysis gives a wind field at $500 \mathrm{hPa}$ (representative of the 4-6 km layer) that is almost similar to the $450 \mathrm{hPa}$ and $400 \mathrm{hPa}$ levels (not shown); so, the pattern reproduced by Lagrangian analysis may be qualitatively compared to the observations in the higher layers. This confirms the presence of a W-E pattern above the Himalayan region. Coming back to the $500 \mathrm{hPa}$ levels, despite a substantial agreement for the total frequencies (around $20 \%$ in both simulation and measurements), the spatial distribution shows several discrepancies. Trajectories indicate a main dust belt north of (and partially above) the plateau, while the measurement, in addition to this pattern, shows an accumulation of dust aerosol on the southwest flank, similarly to the $700 \mathrm{hPa}$ layer. The discrepancy can be again attributed to a bias coming from the vertical resolution of the wind fields that, at $500 \mathrm{hPa}$, makes the influence of the mechanical obstacle of the plateau less relevant with respect to the real atmospheric circulation. Moreover, the contribution of the high-level jet may be overestimated, leading to a more efficient westerly transport. There is still a small amount of dust coming from the local deserts that can reach the northern side of the Himalayan Plateau (less than $10 \%$ ), but, at this height, its contribution is less relevant. Smoke is found with similar percentages to the observations but, as for the $700 \mathrm{hPa}$ layer, is located slightly north of the measurements.

\section{Conclusions}

The CALIOP observations in the Himalaya region allow the analysis of the spatial distribution and the seasonal and monthly variability of different forms of atmospheric aerosol, identified on the basis of the observed optical parameters. Dust is found to be the most probable type in the wider Himalayan Plateau region with a marked seasonal cycle, mainly modulated by the seasonality of the monsoon with a maximum in spring (reaching around $75 \%$ ), and is observed preferentially southwest and north of the plateau. In the same season it reaches also its maximum above the plateau with a not negligible frequency of occurrence (around 20\%). Pol- luted dust, which is characterized by values of optical parameters intermediate between smoke and dust, is mainly observed in northern India. The value of occurrence of polluted dust, in general, lies between those found for the two other types, while its annual cycle is often less marked, nonetheless with a behavior similar to the smoke aerosol. Smoke particles have a lower occurrence with respect to dust, with an occurrence related to the cycle of emissions of anthropogenic and biomass burning and a maximum during the summer season (reaching an occurrence frequency of around $25 \%$ ). Polluted dust and smoke are observed over the plateau mainly in summer with lower values (maximum of 10 and $5 \%$, respectively). Trajectories cluster analysis is directly compared to the observed occurrence frequency and, in general, a satisfactory agreement is found, supporting the use of Lagrangian calculations for the interpretation of the observed aerosol patterns. Discrepancies seem to arise from limitations of the transport (limited vertical resolution, uncertainty on emissions, inaccuracy of transport pattern leeward of the plateau). Transport analysis shows that in the lower atmospheric layers dust particles originate from closer sources (Taklamakan and Gobi deserts for the northern area and south-central Asia for the southern area), while in upper layers a substantial fraction of dust particles may originate from PBL above the Arabian and Sahara deserts and be subsequently advected north of the plateau. During spring transport occurs through the pattern of a W-E corridor surrounding the plateau and dividing into two branches. The northern branch is fed by dust coming from the local deserts with a likely role in determining the maximum dust occurrence above China during spring season. Smoke, mainly emitted in northern India and China, can be partly conveyed by the southern branch and is preferentially observed southeast of the plateau, where strong sources are present. Despite the limited length of the observational time series, it is possible to clearly identify differences in aerosol occurrence among the 4 years. The years 2007 and 2008 have larger observational frequencies for each of the aerosol types throughout the region. The underlying mechanism is not fully clarified as transport does not show any clear differences between the high- and low-occurrence years. Similarly, interannual differences in precipitation above source regions during the pre-monsoon season are suggestive but not conclusive to explain a possible modulation of the intensity of dust sources. Overall the analysis presented here provides an extension of the intraseasonal dust characterization reported in previous works, giving an assessment of the variability of different particle types and identifying marked interannual differences. Lagrangian analysis supported the identification of the main transport patterns, highlighting the possible role of long-range transport in dust distribution in the Himalayan Plateau region. The diagnostics derived from observations on a regular geographical grid may be directly compared to global aerosol model output, in order to quantify models' ability to reproduce aerosol distribution, its variability and 
the possible sources in the hot spot climatic region of the Himalayan Plateau.

Acknowledgements. The work is partly funded by the EVK2-Share project Paprika and the MIUR project NextData. CALIPSO data were obtained from the NASA Langley Research Center Atmospheric Science Data Center. MACCity emissions come from the ECCAD program. ECMWF data used in this study have been obtained from the ECMWF Data Server.

Edited by: C. Barbante

\section{References}

Bergman, J. W., Fierli, F., Jensen, E. J., Honomichl, S., and Pan, L. L.: Boundary layer sources for the Asian anticyclone: Regional contributions to a vertical conduit, J. Geophys. Res.-Atmos., 118, 2560-2575, doi:10.1002/jgrd.50142., 2013

Bollasina, M., Sumant N., and Lau, K.-M.: Absorbing Aerosols and Summer Monsoon Evolution over South Asia: An Observational Portrayal, J. Climate, 21, 3221-3239. doi:10.1175/2007JCLI2094.1, 2008

Bonasoni, P., Cristofanelli, P., Marinoni, A., Pradhan, B. B., Fuzzi, S., Gobbi, G. P., Vuillermoz, E., and Laj, P.: High Concentration of Black Carbon Observed in the High Himalayas, UNEP Black Carbon E-bulletin, Vol. 2, July 2010.

Dey, S. and Di Girolamo, L.: A climatology of aerosol optical and microphysical properties over the Indian subcontinent from 9 years (2000-2008) of Multiangle Imaging Spectroradiometer (MISR) data, J. Geophys. Res., 115, D15204, doi:10.1029/2009JD013395, 2010.

Diehl, T., Heil, A., Chin, M., Pan, X., Streets, D., Schultz, M., and Kinne, S.: Anthropogenic, biomass burning, and volcanic emissions of black carbon, organic carbon, and $\mathrm{SO}_{2}$ from 1980 to 2010 for hindcast model experiments, Atmos. Chem. Phys. Discuss., 12, 24895-24954, doi:10.5194/acpd-12-24895-2012, 2012.

Eck, T. F.,Holben, B. N., Dubovik, O., Smirnov, A., Goloub, P., Chen, H. B., Chatenet, B., Gomes, L., Zhang, X.-Y., Tsay, S.C., Ji, Q., Giles, D., and Slutsker, I.: Columnar aerosol optical properties at AERONET sites in central eastern Asia and aerosol transport to the tropical mid-Pacific, J. Geophys. Res., 110, D06202, doi:10.1029/2004JD005274, 2005.

Gautam, R., Hsu, N. C., Lau, K. M., Tsay, S. C., and Kafatos, M.: Enhanced pre-monsoon warming over the Himalayan-Gangetic region from 1979 to 2007, Geophys. Res. Lett., 36, L07704, doi:10.1029/2009GL037641, 2009.

Granier, C., Bessagnet, B., Bond, T., D’Angiola, A., van der Gon, H. D., Frost, G. J., Heil, A., Kaiser, J. W., Kinne, S., Klimont, Z., Kloster, S., Lamarque, J.-F., Liousse, C., Masui, T., Meleux, F., Mieville, A., Ohara, T., Raut, J.-C., Riahi, K., Schultz, M. G., Smith, S. J., Thompson, A., van Aardenne, J., van der Werf, G. R., and van Vuuren, D. P.: Evolution of anthropogenic and biomass burning emissions of air pollutants at global and regional scales during the 1980-2010 period, Clim. Change, 109, 163-190, doi:10.1007/s10584-011-0154-1, 2011.

Kaufman, Y. J., Tanre, D., and Boucher, O.: A satellite view of aerosols in the climate system, Nature, 419, 215-223, 2002.
Kayetha, V. K., Senthil Kumar, J., Prasad, A. K., Cervone, G., and Singh, R. P.: Effect of dust storm on ocean color and snow parameters, J. Ind. Soc. Rem. Sens., 35, 1-9, 2007.

Koffi, B., Schulz, M., Breon, F. M., Griesfeller, J., Winker, D., Balkanski, Y., Bauer, S., Berntsen, T., Chin, M., Collins, W. D., Dentener, F., Diehl, T., Easter, R., Ghan, S., Ginoux, P., Gong, S., Horowitz, L. W., Iversen, T., Kirkevag, A., Koch, D., Krol, M., Myhre, G., Stier, P., and Takemura, T.: Application of the CALIOP layer product to evaluate the vertical distribution of aerosols estimated by global models: AeroCom phase I results, J. Geophys. Res., 117, D10201, doi:10.1029/2011JD016858, 2012.

Krinner G., Boucher O., and Balanski Y.: Ice-free glacial northern Asia due to dust deposition on snow, Clim. Dynam., 27, 773777, 2006.

Kuhlmann, J. and Quaas, J.: How can aerosols affect the Asian summer monsoon? Assessment during three consecutive premonsoon seasons from CALIPSO satellite data, Atmos. Chem. Phys., 10, 4673-4688, doi:10.5194/acp-10-4673-2010, 2010.

Lamarque, J.-F., Bond, T. C., Eyring, V., Granier, C., Heil, A., Klimont, Z., Lee, D., Liousse, C., Mieville, A., Owen, B., Schultz, M. G., Shindell, D., Smith, S. J., Stehfest, E., Van Aardenne, J., Cooper, O. R., Kainuma, M., Mahowald, N., McConnell, J. R., Naik, V., Riahi, K., and van Vuuren, D. P.: Historical (1850-2000) gridded anthropogenic and biomass burning emissions of reactive gases and aerosols: methodology and application, Atmos. Chem. Phys., 10, 7017-7039, doi:10.5194/acp10-7017-2010, 2010.

Lau, K. M., Kim, M. K., and Kim, K. M.: Asian summer monsoon anomalies induced by aerosol direct forcing: the role of the Tibetan Plateau, Clim. Dynam., 26, 855-864, doi:10.1007/s00382006-0114-z, 2006.

Lau, K.-M., Tsay, S. C., Hsu, C., and Chin, M.: The Joint Aerosol-Monsoon Experiment: A new Challenge for monsoon climate research, B. Am. Meteorol. Soc., 89, 369-383, doi:10.1175/BAMS-89-3-369, 2008.

Liu, D., Wang, Z., Liu, Z., Winker, D., and Trepte, C.: A height resolved global view of dust aerosols from the first year CALIPSO lidar measurements, J. Geophys. Res., 113, D16214, doi:10.1029/2007JD009776, 2008

Menglin J.: MODIS observed seasonal and interannual variations of atmospheric conditions associated with hydrological cycle over Tibetan Plateau, Geophys. Res. Lett., 33, L19707, doi:10.1029/2006GL026713, 2006

Menon, S., Hansen, J., and Nazarenko, L.: Climate effects of black carbon aerosols in China and India, Science, 297, 2250-2253, 2002.

Mishra, A. K. and Shibata, T.: Climatological aspects of seasonal variation of aerosol vertical distribution over central IndoGangetic belt (IGB) inferred by the space-borne lidar CALIOP, Atmos. Environ., 46, 365-375, 2012.

Naz, S. B., Bowling, L. C., and Crawford, M. M.: Spatial and temporal glacier changes in the Karakoram Himalaya derived from Landsat satellite data. J. Glaciol., submitted, 2011.

Omar, A. H., Winker, D. M., Tackett, J. L., Giles, D. M., Kar, J., Liu, Z., Vaughan, M. A., Powell, K. A., and Trepte, C. R.: CALIOP and AERONET aerosol optical depth comparisons: One size fits none, J. Geophys. Res., 118, 4748-4766, doi:10.1002/jgrd.50330, 2013. 
Prasad, A. K., Singh, R. P., and Singh, A.: Seasonal climatology of aerosol optical depth over the Indian subcontinent: trend and departures in recent years, Int. J. Remote Sens., 27, 2323-2329, 2006 b.

Raina, V.: Himalayan Glaciers A State-of-Art Review of Glacial Studies, Glacial Retreat and Climate Change, Geological Survey of India, retrieved 10 January, 2010.

Ramanathan, V., Chung, C., Kim, D., Bettge, T., Buja, L., Kiehl, J. T., Washington, W. M., Fu, Q., Sikka, D. R., and Wild, M.: Atmospheric brown clouds: Impacts on South Asian climate and hydrological cycle, P. Natl. Acad. Sci. USA, 102, 5326-5333, doi:10.1073/pnas.0500656102, 2005.

Ramanathan, V., Li, F., Ramana, M. V., Praveen, P. S., Kim, D., Corrigan, C. E., Nguyen, H., Stone, E. A., Schauer, J. J., Carmichael, G. R., Adhikary, B., and Yoon, S. C.: Atmospheric brown clouds: Hemispherical and regional variations in long-range transport, absorption, and radiative forcing, J. Geophys. Res., 112, D22S21, doi:10.1029/2006JD008124, 2007

Schuster, G. L., Vaughan, M., MacDonnell, D., Su, W., Winker, D., Dubovik, O., Lapyonok, T., and Trepte, C.: Comparison of CALIPSO aerosol optical depth retrievals to AERONET measurements, and a climatology for the lidar ratio of dust, Atmos. Chem. Phys., 12, 7431-7452, doi:10.5194/acp-12-7431-2012, 2012.

Shrestha, P. and Barros, A. P.: Joint spatial variability of aerosol, clouds and rainfall in the Himalayas from satellite data, Atmos. Chem. Phys., 10, 8305-8317, doi:10.5194/acp-10-8305-2010, 2010.
Stohl, A.: Computation, accuracy and applications of trajectories a review and bibliography, Atmos. Environ., 32, 947-966, 1998. van der Werf, G. R., Randerson, J. T., Giglio, L., Collatz, G. J., Kasibhatla, P. S., and Arellano Jr., A. F.: Interannual variability in global biomass burning emissions from 1997 to 2004, Atmos. Chem. Phys., 6, 3423-3441, doi:10.5194/acp-6-3423-2006, 2006.

Winker, D. M., Hunt, W. H., and McGill, M. J.: Initial performance assessment of CALIOP, Geophys. Res. Lett., 34, L19803, doi:10.1029/2007gl030135, 2007.

Winker, D. M., Tackett, J. L., Getzewich, B. J., Liu, Z., Vaughan, M. A., and Rogers, R. R.: The global 3-D distribution of tropospheric aerosols as characterized by CALIOP, Atmos. Chem Phys., 13, 3345-3361, doi:10.5194/acp-13-3345-2013, 2013.

Xia, X., Wang, P., Wang, Y., Li, Z., Xin, J., Liu, J., and Chen, H.: Aerosol optical depth over the Tibetan Plateau and its relation to aerosols over the Taklimakan Desert, Geophys. Res. Lett., 35, L16804, doi:10.1029/2008GL034981, 2008

Xu, B., Cao, J., Hansen, J., Yao, T., Joswia, D. J., Wang, N., Wu, G., Wang, M., Zhao, H., Yang, W., Liu, X., and He, J.: Black soot and the survival of Tibetan glaciers. P. Natl. Acad. Sci., 106, 22114-22118, doi:10.1073/pnas.0910444106, 2009. 